\title{
Critique on Developments in the Mechanization of Information Systems
}

$\mathrm{T}$ HE DEVELOPMENT of microreproduction, computing machines, and similar devices has stimulated the imagination of scientists, management experts, and librarians concerned with problems of handling research information. It is evident from previous reports that we have moved from imaginative visions to practical uses for machines in the handling of communication problems. In each development we assume that the mechanical device has directly contributed to the efficiency of the work performed. However, many of us watching these pilot programs do not have sufficient data from the individual experiments to determine what applications they might have for our work. When the cumulative effect of small staffs and increased workloads directs us toward automation, we are blocked by a lack of specificity, clarity, and practical data of progress by those using machines.

Again, when we attempt to form an integrated picture of the total progress in the use of automation in information handling, we are baffled not only by the rapid development of new experimental techniques and the highly specialized application of many of the experiments, but most formidably by esoteric jargon. The air for many of us was cleared by Bar-Hillel's article, “A Logician's Reaction to Recent Theorizing on Information Search Systems," particularly his statement:

The inclination to seek a remedy for the present unsatisfactory situation of infor-

Mr. Mohrhardt is Director, U. S. Department of Agriculture Library. mation searching by "going to the fundamentals" seems to have been reinforced by the use of certain fashionable phrases and slogans that sound appealing enough as long as their inherent vagueness and lack of clarity is not exposed. I am referring to such catch words as "semantic" and "structure," to such statements as "information retrieval systems should not concern themselves with words but with concepts," and to the invocation of Boolean Algebra and Symbolic Logic.1

I present my plea, or critique, as one of the potential users of these devices, who seeks guidance through the morass of vagueness to a ground of understanding. ${ }^{2}$

President Clyde Williams of Battelle Memorial Institute, at an ACS Symposium in 1954, gave the practical basis for our interest in his statement:

But the chief reason for management's interest is the mounting cost and the complexity of literature studies. The volume of technical literature in our libraries is becoming so great that the mere process of finding what is needed at a given time often is exceedingly costly. It has been estimated, in fact, that in some instances as much as one-third of the cost of a research investigation may be absorbed in literature searching. This is probably the extreme, but to the cost of literature searching must be added the cost of maintaining a library and finally the cost of assimilating the literature retrieved. As the cost of searching, plus the cost of maintenance, plus the cost of assimilation, approaches the cost of repeating the work,

1 Yehoshua Bar-Hillel, “A Logician's Reaction to Recent Theorizing on Information Research Systems," American Documentation, VIII (1957), 104.

2 Paper presented at a "Symposium on Mechanized Data Handling" before the Division of Chemical Literature, American Chemical Society, New York, September $10,1957$. 
the value of a technical library declines. Unless there is a net gain in the "technical energy" required to retrieve and assimilate accumulated information over what might be used in repeating the work, the library has not fulfilled its function. ${ }^{3}$

The implied challenge applies both to the developers and ultimate users of new techniques which will reduce the time and cost of these searches. Many of us who cannot afford experimentation are anxious to consider the adoption of these new devices, but we need more information than is now available. The planners and developers, as well as those who are experimenting with methods and machinery for handling information, should provide extensive factual data on both the economic and sociological aspects of use.

To make an economic evaluation of the new device we need to know:

1. Conversion costs from the conventional to the new system.

2. Whether the new system fully replaces the old method or provides partial supplementary assistance.

3. The effect on staff size.

4. The effect on the type of staff needed and how the old staff will be utilized.

5. Complete and objective cost figures.

6. Physical characteristics of equipmentweight, size, special wiring, etc.

7. Comparative time needed to provide comparable service under the old and new systems.

8. Present status of the machine-experimental or commercially available.

9. Adaptability and limitations of the equipment.

Having established the efficiency rating of a machine, we should be equally interested in the reactions of those whom it serves. Concern with the personal reaction of the ultimate consumer-the research worker or scientist-is not theoretical. Studies in research methods have shown that scientific research follows no set pattern and is a highly individualized

\footnotetext{
${ }^{3}$ Clyde Williams, The Problem of Literature Organi zation-from the Viewpoint of Management. (Colum bus, Ohio: Battelle Memorial Institute, 1954.)
}

procedure. The importance of this as related to machines was pointed out by Dr. J. E. Burchard:

The benign chance must not be dismissed as a wrong way. Conceivably, the human being what he is, it may be the best way. It is not to be hoped that the mechanical proposals .... are ever to replace this last way of finding what one ought to read.

Indeed so much reliance is placed upon the benign hazard by many first-rate scientists that it is not at all uncommon to find men of the first class who do not believe that more organized and more rapid methods of search are even necessary or desirable. Nor is it enough to say that these men are reactionary or smug.

Indeed my personal impression is that a very substantial number of the best of the working scientists are not convinced that the situation is in any way one of crisis. Most scientists, when pressed, will admit that more is published which might interest them than they ever see. But it does not follow, they argue, that drastic measures need be taken. In fact, the greatest pressure for improved techniques has been exerted by a relatively few scientists and engineers, including especially the distinguished American, Vannevar Bush, and by a large number of librarians. ${ }^{4}$

Dr. Bush is unquestionably the originator and stimulator of much of the work in this area. However, even his proposals are essentially conservative when compared to those of some of the machine enthusiasts. Two of Dr. Bush's statements indicate his limitations on the use of machines in this field:

There is no reason why Man should not relegate to the machine all those parts of his processes of cerebration which are repetitive in nature, or subject to exact formulation. 5

For mature thought there is no mechanical substitute. But creative thought and essentially repetitive thought are very dif-

\footnotetext{
"J. E. Burchard, "The Waterloo of Science," Revue de la Documentation, XVI (1949), 96.

'Vannevar Bush, Today's Research and Tomorrow's World. (Stanford, Calif.: Stanford Research Institute,
} 1954), p. 12. 
ferent things. For the latter there are, and may be, powerful mechanical aids. ${ }^{6}$

Since creative research has never followed a precise methodology and has depended upon cross fertilization and chance association of ideas, one may well question the extent to which research workers should be encouraged to depend upon automation in research endeavor.

Caution is further advised in reporting on new projects and machines. $\mathrm{Re}$ ports on automation are confusing not only because of their jargon but often because of a lack of critical analysis. Some verbal reports have inadvertently been misleading. A good example is the mechanical translation field where there appears to be a general idea that a machine will shortly be available which will accept articles written in foreign languages and automatically provide them to us in usable English. Careful study of reports shows, however, that many provisos pertaining to this statement are minimized or at least not properly stressed. Actually, present translation machines are only useful when the following conditions are met: (1) The article must be written in a limited vocabulary. (2) The article must be preedited for insertion in the machine and it must later be post-edited after the machine has completed its work. There are still many unsolved problems in sentence structure and word content that have not been satisfactorily solved for machine application. I doubt that there is any immediate prospect that machines will solve this problem for us.

Relatively few of us will be able to justify elaborate equipment until we are better informed about the costs of conventional library search and the actual savings which they provide in the total research project. A factory manager can easily justify new equipment that will cut down the cost of a $\$ 150,000$ steel

- V. Bush, Endless Horizons. (Washington, D. C.: Public Affairs Press, 1946), p. 24. forging. If we are to justify automation in information and library work, it will be necessary for us to accumulate objective data indicating the economic importance of using recorded information in current research studies.

For most of the libraries, documentation centers, and information centers in this country, our immediate needs are for minor improvements that will enable us to carry on our current work in a more effective manner. The Western Reserve Center for Documentation and Communication Research has summarized the general needs as follows:

We have not suggested doing away with the older bibliographical services and techniques. Most of them will continue to serve adequately in limited spheres for a long time to come. The new systems may in a few instances replace older services, but in many more instances they will supplement or implement more familiar types of services. ${ }^{7}$

This is a reassuring statement for many of us who have not been certain about the perspective of the documentation centers. We have seen instances where emphasis on devices and methods has obscured our objectives. All of us working in this field can subscribe to Dr. Bush's statement:

Civilization proceeds because Man can store, transmit, and consult the record because the accomplishments of one generation are available to the next, because every man can share the experience of his fellows. 8

Whether we are using manual or machine methods, each of us is concerned with making it possible to "share the experience of his fellows." Our objective is clear, and it is hoped that we can be satisfied with gradual and steady progress in a civilization that daily becomes more complex.

\footnotetext{
7 Yehoshua Bar-Hillel, "Center for Documentation and Communication Research. Comments on 'A Logician's Reactions," American Documentation, VIII (1957), 122 .

8 Vannevar Bush, Today's Research and Tomorrow's World, p. 13.
} 